Shahid Kardar 99

\title{
Empowering People: How?
}

\section{Shahid Kardar*}

Few would deny that there is increasing disillusionment with democracy as practised today in Pakistan. The experience with dictatorships has been equally disenchanting. Since both dictatorships and elected governments have failed, a common refrain these days is the need to empower people through democratisation, decentralisation and opening up of new avenues for participation in politics to enable them to change their own destinies.

Although the Constitution of Pakistan bestows a host of rights in all citizens, for the vast majority these rights exist only on paper. The common lament in this case is that creating rights is one thing, implementing them and enabling people to secure and exercise these rights is quite another. Used in this sense, the concept of empowerment seems to involve the building up of the economic, social and political capability of all segments of society, including, above all, the marginalised and less organised groups and social classes, since not only are there deeprooted inequalities of income and wealth (with over one-third of the population living below the poverty line), inequalities are also built into the traditional structure of society based on gender, religion and ethnic background. In other words, the concept has become a catchall slogan that carries different meanings in different situations on who is to be empowered and how. What does the term mean? Have we sloganised a terminology that only manifests itself meaningfully when applied to Western societies and polities and gets devoid of its intrinsic character when applied to our social, political and economic structures? What forms can it acquire here to take on a character more in tune with our institutional framework and social and cultural values?

The above questions are relevant for a discussion on empowerment in our environment, since the accomplishment of social transformation, especially of the economically disadvantaged groups, as a way of empowering people, will require a rearrangement of the power structures. What would the new underlying relationships and power structures look like? How would the role of the State be redefined and re-configured? How do we build these new, but basic, institutions of good governance that ensure a fair deal for all, and particularly for the handicapped sections of society? Since rights are a product of social relations, will the entrenched groups in society meekly

\footnotetext{
${ }^{*}$ Director of Systems (Private) Ltd., currently, Minister of Finance, Government of Punjab.
} 
accept demands for transforming the social order without putting up a fight? Can the existing systems and institutional structures of criminal justice and administration, which are not independent of the executive, ensure the protection of the various rights granted by the country's Constitution and supporting framework of legislation? All these questions require clear answers, since the manner in which the concept of empowerment has been expounded to-date seems to suggest that it is both a means to an end as well as an end in itself. And since the broad objectives associated with the concept include the enhancement of the civil, political, economic and social rights of the people, we need to see what ways have been devised domestically to first secure and then expand these rights. How successful have these efforts been? In which direction should we be moving in the future?

As indicated above, the need for elaborating on the concept has arisen from the huge gap, if not contradiction, between the procedural features of the democratic political system in the country, i.e., the formal aspects of political participation, on the one hand, and the extent of democratisation of the political culture, the society and the institutions of the state, i.e., the degree to which political participation is effective, on the other. It is not that there have been no improvements over time (described later below) but that these changes have been marginal in comparison with the expectations aroused in 1947, and are also the need of the hour. For instance, electoral voting, one of the processes for democratic participation has been in practice for some time and has had some successes to its credit, but the achievement has been far less than its promise and the expectations that were linked to it. For ordinary voters the attraction for participation has withered over time, since change in governments has not meaningfully altered their lives. It is not that the political and state structures have completely ignored these demands. They have accommodated some of these demands, with the different groups (in particular the different nationalities) articulating their grievances more stridently and vociferously, although these concessions were made reluctantly, haltingly and, in effective terms, inadequately and well below the quality and level of participation demanded in the decision-making processes and structures.

At one level these structures established and nurtured a system of quotas to empower disadvantaged groups, identified on the basis of their place of birth. Quotas are supposed to empower these groups (by selecting the most meritorious among them) by ensuring an equitable representation of the different nationalities in the decision-making structures and key institutions managed by government - the civil bureaucracy and public sector enterprises. 
At the political level, the State structures gave representation to different nationalities (identified through their provincial/administrative links) in parliament - in the National Assembly on population basis and in the Senate in equal numbers. At yet another level, an institutional framework was set up, in which provinces were granted a measure of autonomy. To enable people at the local level, remote from the provincial capitals, to organise their lives, the provincial structures were further decentralised by creating a more basic representative unit of government, the local government.

However, as argued above, none of the Constitutional arrangements has come up to peoples' expectations. One reason for the nature and scale of the problem is the weak rooting of the concepts of civil, political and social rights in our social order. These concepts are relatively new for both society and politics. Within the prevailing social order individual freedoms have traditionally been subordinate to group or community rights. The building blocks of our social order have been groups as opposed to individuals as autonomous entities and agents and the relationship between the individual and society is largely mediated through the biradari, tribe, family or the community. Empowerment as an alternative, using modern symbols and institutional arrangements, will require a slow dismantling of these social structures before new ones can be firmly put in place. In industrialised societies, the middle class is the moving spirit of a democratic system, since it has a vested interest in it. In societies where such a middle class is still in its early stages of formation, what supposedly constitutes our "national polity" manifests itself in the form of the above referred ethnic, biradari and tribal loyalties.

The discussion above raises an obvious question. Should we create new institutions or can we place our hopes for the future on existing institutions, which can, supposedly, after some modifications and changes, ensure the development of participatory, transparent and accountable systems and structures of governance? If the presently inefficient existing institutions and systems can perform the new role being envisaged, how will they have to be reformed, since empowerment of people will work only if legislatures, policing and legal and judicial systems function properly? A functional legal system to enable and further such empowerment and a political system that allows the legal and judicial apparatus to function independently are part and parcel of what constitutes the essential ingredients for the successful empowerment of people. But if these institutions and procedures are to be reformed, is it more important to perform this task in a piecemeal fashion, or at the lowest level first or should the underlying issues be addressed at all levels of the hierarchy simultaneously? 
Moreover, real empowerment of people can only be achieved if they are literate, healthy and capable of exploiting economic opportunities. So, what political, social and cultural structures, institutional arrangements, mechanisms and systems will enable us to educate our population, establish a rule-based political order and ensure the development of a neutral and independent police and an impartial and independent judiciary? Can an impartial system of policing and a just legal and judicial system be established without new reform criteria, in terms of qualifications, credentials and training for screening both new entrants and existing cadres of the police and the judiciary?

Some of the more vocal and articulate voices in civil society, with the support of donors, are also advocating other mechanisms and initiatives to empower people. The most important of these are provision of micro credit, poverty alleviation programmes and development and management of economic and social services through community participation. The government is also supporting some of these initiatives through SAP (Social Action Programme) and the newly established Poverty Alleviation Fund. But such governmental efforts to avowedly empower ordinary people contradict a host of other attempts to either centralise or weaken endeavours to decentralise, e.g. the $15^{\text {th }}$ amendment, the strategy currently operational in Sindh, the attempt in the recent budget to impoverish local governments by abolishing Octroi and Zilla Tax, etc. How can such tendencies coexist? Empowerment of people can only be achieved if policies and strategies proceed in tandem and efforts are dovetailed to ensure that all initiatives are nudging society in the same direction. Which raises the question how to link these informal structures and mechanisms with the formal institutional framework and systems, to make the effort of civil society institutions to empower people meaningful and effective?

There is little doubt that in a country of Pakistan's dimensions and diversity ultimately only the government machinery can reach all sections of society. And there is no method for empowering the rural poor nationwide that can completely bypass the bureaucracy and the government. Hence, the need to improve the social composition of the membership in the strategic public sector institutions. However, this may be easier in some institutions compared to others. For instance, the different groups in society can be more easily accommodated in Parliament than in say PIA or the Atomic Energy Commission.

Although under the Constitution the rights of citizenship are vested in individuals, irrespective of sex, race, religion and creed, there is moral support for policies that grant precedence to the rights of some groups in the name of social justice. As mentioned earlier, our way of empowering 
certain groups in the name of social justice has been through a system of quotas.

Part of the demand for quotas in public service stems from the mindset that expects the state to act as the employer of last resort, and sees expansion of government as the answer to unemployment. Although new opportunities have arisen, the attraction for government service has not diminished, largely in part because of lack of institutional mechanisms for ensuring the accountability of public servants. Moreover, since the middle class was essentially created by the state (through provision of employment in the public sector) and did not emerge from the dynamic process of growth it has, as yet, not come around to believing that it can advance without State patronage; thereby providing one of the explanations for the urge to acquire control over State institutions.

This empowerment of groups based on their place of birth through the system of quotas is in conflict with, and discriminates against, the Constitutional provision for equality of opportunity for all citizens; that the quota system as implemented, functioned poorly and did not address the issues which had led to its construction, is another matter. Also, merely bringing about a change in the social composition of an organ of the State or public sector may not be enough to bring about a transformation in the way in which power is exercised, and the manner in which authority is dispersed.

Instead of the system of quotas being phased out after 20 years, it has been extended for an additional 40 years in the interest of equality, social justice and greater representativeness of institutions. As a result, the rights of citizenship have been sacrificed in the interest of group rights symbolised by quotas on the basis of regional backgrounds/domiciles, with all the inherent implications for the efficiency of services provided by public sector agencies. However, this demand for quotas will get diluted over time as the role of the private sector in the economy is expanded, public sector enterprises are privatised, and the scope of provincial autonomy and decentralisation is extended, the latter through the administrative and financial strengthening of the lower tiers of government.

The legitimacy of the government and the effectiveness of parliament as an instrument in policy making and the manner in which the executive views this role, including the extent to which it is representative of the demographic and social structures (and the changes taking place in them over time), is important for creating the legitimacy of the political structures. 
A political order can only be sustained over time if it acquires legitimacy through its wide acceptance as fair and equitable. In our case, the moral legitimacy of the system has been progressively undermined over time. There is a sense of helplessness that the political and social order cannot be transformed simply through holding elections regularly or by enacting good laws. Although the economics of the market is excluding the poor, the politics of democracy is including them. The rich and the professional middle classes, though small in number, play a more dominant role in the market. But the poor, large in number, now have a stronger voice in politics, and hence the mismatch. This has been partly responsible for the change in the social composition of the leadership in the political parties making it more accessible to the people. However, these developments have not led to any great enhancement in the political power of ordinary voters. Economic reforms that ignore the social and political dimensions are destined to fail. Consequently, the radical transformation in the political structures required for empowerment will involve changes in the social composition of the key institutions in society and, particularly, in the state structure and its institutions.

Will the change that people are looking for come from some other mechanisms, processes and institutional arrangements? Perhaps this realisation and the sense of resignation, especially with the evident failure of secular and liberal thought to provide an alternative, provides one possible explanation to the growing numbers of youth aligning themselves with the right wing parties. The social composition of the leadership of these parties appears to be less alien, more open and has seemingly demonstrated greater capacity to absorb the growing numbers of educated youth from middle income households, whose accommodation and upward mobility would be highly restricted in the formal and more well-established political parties where hereditary, filial and social class relations count for more.

Under the present structure, power is centralised either in Islamabad or at the provincial headquarters whereas people are located at the local level. The power that people can practically exercise at the local level cannot check the political power of those located at higher levels. Electoral reform and an active judiciary, can, at best, address the symptoms. The solution lies in changing the role of ordinary people from passive recipients of services to active participants in the conceptualisation, design and delivery of services, i.e., by empowering them. Which means that power will have to be brought down to them through minimum governance from Islamabad or the provincial capitals. This will have to be achieved through a restructuring government, requiring, as a pre-requisite, a reduction in the importance of Islamabad and the provincial capitals, such that the political, economic and service delivery systems become more responsive to citizens' demands. 
The level of provincial autonomy and the limitations within which it is allowed to be exercised has further charged the environment already characterised by disgruntlement and a sense of alienation in the provinces. This has manifested itself in the growing stridency in the demand for greater devolution, especially owing to the ham-handed execution of a strategy under which representative government at all levels is somehow good for the Punjab but not for the other provinces. The political and State structures hold elected institutions in contempt. Only this can explain why it is easier to dismiss elected governments (at all levels) than a clerk in government service-where elaborate procedures come into play to protect even those patently corrupt.

Greater decentralisation is widely regarded as the panacea for these problems. If decentralisation is the answer to some of our major problems, what should decentralisation mean in the context of Pakistan? What form should it assume? Is the present political and administrative structure of local institutions sufficiently representative and adequately equipped to fulfill the functional obligations that they are being expected to perform? There is enough evidence of the growing criminalisation of our political structures, especially at the level of local governments. The dubious credentials of those who presently constitute the Pakistani class of local "notables" prompt many to express concern on the limits, and pace, of decentralisation, suggesting that the tasks of selecting the functions and powers to be decentralised and assigned to local governments and the phasing and sequencing of this mandate would require careful handling. To illustrate, there would be a great deal of apprehension in transferring law and order and policing functions- and the authority to control and exert force- to local governments controlled by shady characters protected by "local representatives".

If existing institutions, and those voted into them, are not adequately representative and do not articulate the dominant views within their constituencies, how do we improve their representativeness? If electoral reform is not the answer - which, based on similar experiences of so many other countries, it clearly is not- how do we get representative institutions to articulate the views of civil society? Since civil society institutions cannot substitute the State, how can inputs from such institutions find formal recognition in the institutional arrangements, i.e., how will the system internalise these inputs? Who will articulate these views? Even if they function essentially as watchdogs and resource centres, do civil society organisations have adequate capacities (in issue analysis, advocacy and outreach) to play their potential role in the formulation and implementation of public policy? Are there organised groups within civil society with the kind of integrity and credibility- both responsive and 
106 The Lahore Journal of Economics, Vol.4, No.2

accountable to the stakeholders- to stake a claim to some legitimacy to lobby and pilot these causes? Having raised more questions than provide answers for, this article will restrict itself to an examination of the issue of decentralisation focusing on the devolution of powers to local government institutions. Future articles will attempt to address the unanswered questions in detail.

\section{Decentralisation-Part II}

There is little doubt that the political and administrative machineries of the federal and provincial governments have become excessively flabby, that has resulted in the development of a situation in which we have one public servant for every 35 Pakistanis. They have over-burdened themselves with functions that fall naturally within the functional domain of local governments. Decentralisation in these circumstances can, therefore, be expected to reduce workload and congestion in the channels of administration and communication. Efficiency requires a centralised revenue collecting system but a decentralisation of expenditures on services; the latter because of the variations between the needs of different areas and because locals can best determine their own needs and priorities. It will also increase efficiency in the provision of services, particularly in the case of services which are not characterised by significant economies of scale and the coverage of which is essentially limited to small jurisdictions.

Moreover, in the 52 years after independence practical problems of administration, governance and development along with people's aspirations for power sharing and the growing demand for widening of space for people's organisations have underlined the need for decentralisation.

However, in Pakistan, the attempts to decentralise authority have at best been halting, few and far between, and generally in the form of administrative solutions rather than decentralisation of political power. Whereas there has been a legal transfer of power, in practical and administrative terms local governments are still controlled by the government, i.e., autonomy exists in form but not in reality. Both hierarchically and through institutional arrangements they are subject to political interference by higher levels of government. The regulatory mechanisms available to the provincial government include approval of projects, budgets and taxation proposals of local councils and appointments/ transfers of their key personnel. In addition, there are legislative provisions regarding the supervision and inspection of the councils to their dissolution by the provincial governments. In the rural areas in particular, the power structure is still within the control of the 
district bureaucracy. This is partly because the administrative machinery does not report to a political authority at the local level. Different legal enactments have facilitated this. Checks and balances instead of being internal to local governments are being exercised through an external administrative agency - the bureaucracy.

The legislation cramps their style and restricts their functional freedoms in other ways as well. For instance, not only are there severe restrictions on their ability to borrow, Local Councils are also required to comply with long-winded cumbersome consultative mechanisms before they can revise tax rates. They have to invite public objections to proposals to revise tax rates, both before and after approval by the Council. This institutional arrangement is unique to Local Councils, since such a rule does not apply to other tiers of the system of representative government prevailing in the country, under which governments are accountable to the public through their representatives.

To enable local bodies to function as institutions of self-government a major redistribution of powers will be required in which certain prerequisites will have to be met. These will include clearly demarcated areas of jurisdiction, adequate administrative powers and human and financial resources commensurate with the functional responsibilities delegated to them and autonomy within this structure. All of these will have to be appropriately guaranteed by the Constitution. By devolving power to lower formations of government, decentralisation can become an engine of growth. The dynamics flowing from instituting such a structure can have a chain effect. In this sense, decentralisation is not being viewed from a territorial but an institutional perspective. This strengthening of local councils is also required to strengthen civil society and promote democratic decisions and norms.

Presently, there is major political and bureaucratic resistance- both overt and covert - to the shedding of political and administrative power to lower levels. There is resistance even to fiscal decentralisation. However, despite the several handicaps faced by local governments, the pressure for decentralisation is building up and future policies are more likely to be attuned to greater devolution of power and authority. Some of it is already reflected in the greater political authority and autonomy being exercised today by the provinces.

However, if there is to be a third tier of government, it raises an obvious question whether it should have the same structural features that local governments currently have. Should there be a uniform third tier along the lines of the district government, proposed by some, and should 
the present separate arrangements for urban or rural areas be discontinued? Should the existing institutional arrangements be merely strengthened to improve service delivery or should this capability strengthening be complemented by other structures that improve the accountability of the service providers? The principles that make the functioning of the market and the providers of service more efficient and cost effective in delivering better quality service have somehow to be applied in the case of services provided by the government. Admittedly, this is easier said than done, but few would disagree that those paid from the public purse must be made more accountable to those receiving these services. However, if an alteration of the current arrangements is regarded necessary then, whatever the structure of government at the lowest level, it would have to tackle the following key questions:

a) Should there be a uniform structure for both rural and urban areas? If so, how will cities like Karachi (which currently has five districts) and Lahore and large municipal corporations like Gujranwala, Faisalabad, etc., be accommodated in this framework?

b) A third tier at the district level would be too remote for grass root interaction, a role which union councils in rural areas, because of their proximity to the local population, are better placed to play.

c) How will the employees of the provincial and federal government functioning at the local level be accountable/answerable to, say a district government responsible for providing services that have been transferred to it? The most effective way available to a political setup to exercise control over the bureaucracy is to have powers to recruit, post, transfer and fire. This may require a conversion of the existing provincial cadre of employees to a district cadre. But this will be resented by different categories of civil servants - for fear of the likely impact on seniorities, career paths, future pay scales, pensions that have accrued to date, and perhaps even job security, etc.

d) Urgently, all functions pertaining to general hospitals, metropolitan transport, housing (sites and services) schemes, trunk water, sewerage and drainage systems, civil defence, etc., in the urban areas fall within the functional domain of the provincial government or its agencies. What will be the future of development authorities and water supply and sanitation agencies in the urban areas? Will they continue to exist or will they function under the third tier of government? 
e) Some economic services because of their nature, such as irrigation (which are essentially integrated and inter-linked systems), will be difficult to dissect into separate systems that could be neatly divided amongst local governments for both development and operations and maintenance.

In the light of the discussion above, what functions and administrative responsibilities should form the mandate of the local governments? The economic case for decentralisation justifies the handling over to the lowest tier of government, services, which are based on relatively simple technology, are labour intensive and serve relatively small jurisdictions. Functions that best meet these criteria or guiding principles include primary education, curative health, water supply, drainage and sewerage, etc.

However, in view of the agreement that the Federal Government has signed with the IMF, octroi and export tax, the major sources of revenue for local governments has been abolished after the enhancement in the rate of GST from 12.5 per cent to 15 per cent and the eventual extension in the scope of GST to the services sector. This development will strike a deadly blow to the viability of strong local governments and the potential for empowering people through decentralisation. The local councils will be faced with a major predicament, a revenue setback, at least in the initial years, and will require financial assistance to tide over the adjustment period - which is likely to be much longer than is being envisaged at the moment, even if the income from a particular revenue stream or instrument were to be earmarked for distribution among local governments. The resource transfer arrangement that has been currently designed or likely to be designed in the foreseeable future to replace the revenue foregone by local governments will, by increasing the unpredictability of revenue receipts, enhance their dependence on the federal and provincial governments and compromise their autonomy, if not place them at the mercy of these governments. The mixed experience of local urban councils with respect to property tax transfers from the provincial government and that of the latter on transfers from the NFC divisible pool does not provide a comfortable basis for being complacent about the smooth functioning of such an arrangement. In particular, the operational experience of the NFC Award does not provide succour for establishing a similar framework at the provincial level for "statutory type" transfers to local governments. The arrangement on financial flows will be critical because it will take time to develop an adequate revenue base through a tax sharing or revenue transfer arrangement and additional resource mobilisation measures at the local leve1. 
U1timately, decentralisation is a political decision and its implementation is a reflection of the political structures and processes. Greater participation in development planning and management will result not only in a more efficient and effective utilisation of scarce resources but also promote national unity, by giving different groups in different regions of the country a greater ability to participate in planning and decision making and, thereby, a greater stake in maintaining political stability. A complete decentralisation of services will be difficult to attain in the short to medium term. The demands for resources to finance the recurrent and development budgets as well as the lack of institutional capacity will place limits on the scope of a decentralisation package. 